using a compounder or via other method (8\% each). Organisations not using AIO PN: 43\% of organisations were not planning to use AIO PN or didn't know and $15 \%$ planned to start in the future. $42 \%$ selected 'other' and gave comments, primarily relating to avoiding AIO PN for neonates, e.g. need to use neonatal network PN (split-phase) or prefer flexibility to stop lipid in case of adverse effects. Eleven organisations answered, 'Why are you thinking of using AIO PN?' - examples included releasing aseptic capacity, reducing administration errors/improving safety and the long shelf life of triple-chamber AIO bags.

Conclusion AIO PN appears to be an appropriate and safe for local use and should be taken into account in national standard paediatric PN formulation design where practicable.

\section{P43 CONCENTRATED STANDARDISED PN TO OPTIMISE NUTRITION IN PRETERM INFANTS}

Zoe Price*. University Hospitals Bristol NHS Foundation Trust

10.1136/archdischild-2020-NPPG.52

Background In 2010, the NCEPOD $^{1}$ report demonstrated a lack of good nutritional care for preterm infants. Since that time various approaches have evolved including standardisation of $\mathrm{PN}^{2}$ concentrated standardised $\mathrm{PN}^{3}$ and publication of a national framework from BAPM. ${ }^{4}$ The delivery of nutrition to preterm infants on our unit has been continuously monitored, evaluated and adapted.

Aims The aim of this audit was to evaluate whether reformulating our PN recipes would improve nutritional intake and thus growth parameters over the first 14 days after birth.

Methods Data was collected from our EPMA system and analysed retrospectively from all infants born at our unit $<28$ weeks gestation or $<1 \mathrm{Kg}$ from 16/4/2016 to 15/4/2017 (audit 1) and from $1 / 6 / 2018$ to $31 / 5 / 2019$ (audit 2).

Results Data from a total of 33 patients was analysed using Excel $^{\mathrm{TM}}$. The mean gestation and weight were similar for both audit cycles. Audit 1: gestation 26.5 weeks, weight $0.75 \mathrm{~kg}$; audit 2: gestation 26.7 weeks, weight $0.74 \mathrm{~kg}$. The average time from birth to PN was less in audit 2 (12 hrs 8 mins vs 13 hrs 12 mins), however the time from PN being prescribed to being administered took over 3 times longer $(5 \mathrm{hrs} 1 \mathrm{~min}$ vs $1 \mathrm{hr} 30$ mins). No patient received PN within 6 hours of birth in audit 2 compared to $20 \%$ in audit 1 . The average nitrogen intake was higher in audit 2 than audit $1(0.41 \mathrm{~g} / \mathrm{kg} /$ day vs $0.36 \mathrm{~g} / \mathrm{kg} /$ day) and the highest protein intake increased from $0.55 \mathrm{~g} / \mathrm{kg} /$ day to $0.69 \mathrm{~g} / \mathrm{kg} /$ day respectively; the average energy intake decreased from $73.5 \mathrm{kcal} / \mathrm{kg} /$ day in audit 1 to $68 \mathrm{kcal} / \mathrm{kg} / \mathrm{day}$ in audit 2 . The non-nitrogen energy to nitrogen ratio was lower in audit 2 versus audit $1(165.3 \mathrm{kcal} / \mathrm{g}$ nitrogen vs $204.7 \mathrm{kcal} / \mathrm{g}$ nitrogen). There was no change in the percentage of patients requiring insulin: 40\%. More patients had started receiving lipid infusion in the first 2 days after birth in audit 2 compared to audit 1 (94\% compared to $33 \%)$. Both audits had 2 patients that had still not reached their birth weight by day 14 , however the patients in audit 2 gained on average $9.12 \mathrm{~g} / \mathrm{kg} /$ day compared to $4.96 \mathrm{~g} / \mathrm{kg} /$ day in audit 1 .

Conclusion Reformulating the PN resulted in higher nitrogen intakes and higher weight gain by day 14 , although the full benefit may not have been achieved due to the lower kcal intake and non-nitrogen energy to nitrogen ratio. The time from birth to $\mathrm{PN}$ and the time taken to administer $\mathrm{PN}$ once prescribed were longer so work needs to be done on addressing these issues and reducing barriers to nutrition. The total nitrogen intake with $\mathrm{PN}$ and $\mathrm{EN}$ also needs to be reviewed to prevent excessive nitrogen intake which may result if enteral feeds increase and the rate of $\mathrm{PN}$ is maintained.

\section{REFERENCES}

1. Stewart JAD, Mason DG, Smith N, Protopapa K, Mason N, on behalf of CEPOD 2010. A mixed bag; an enquiry into the care of hospital patients receiving parenteral. https://www.ncepod.org.uk/2010report1/downloads/PN_report.pdf Accessed 03/07/2019

2. Paediatric Chief Pharmacists Group. Improving Practice and Reducing Risk in the Provision of Parenteral Nutrition for Neonates and Children. 2011

3. Morgan C, Radbone L, Birch J. 2016 The Neonatal Parenteral Nutrition (PN) QIPP Toolkit https://www.networks.nhs.uk/nhs-networks/staffordshire-shropshire-andblack-country-newborn/documents/documents/national-toolkit-for-standardising-pn Accessed 03/07/2019

4. British Association of Perinatal Medicine. The Provision of Parenteral Nutrition within Neonatal Services - A Framework for Practice. 2016. https://www.bapm. org/sites/default/files/files/Parenteral\%20Nutrition\%20April\%202016.pdf Accessed 03/07/2019

\section{P44 VACCINE IN PEDIATRIC CHRONIC KIDNEY DISEASE (CKD) AND HEMODIALYSIS}

${ }^{1}$ Aichetou Camara, ${ }^{1}$ Anaïs Razurel, ${ }^{1}$ Christelle Moreau, ${ }^{2}$ Thérésa Kwon, ${ }^{3}$ Marion Caseris ${ }^{4}$ Olivier Bourdon, ${ }^{5}$ Sonia Prot-Labarthe*. ${ }^{1}$ Service de pharmacie, AP-HP, Hôpital RobertDebré, Paris, France; ${ }^{2}$ Service de néphrologie pédiatrique, AP-HP, Hôpital Robert-Debré, Paris, France; ${ }^{3}$ Equipe Opérationnelle d'infectiologie, AP-HP, Hôpital Robert-Debré, Paris, France; ${ }^{4}$ Service de pharmacie, AP-HP, Hôpital Robert-Debré, Département de pharmacie clinique, Université Paris Descartes, Paris, France; ${ }^{5}$ Service de pharmacie, Equipe Opérationnelle d'infectiologie, AP-HP, Hôpital Robert-Debré, Paris France

\subsection{6/archdischild-2020-NPPG.53}

Aims Chronic kidney disease is a major risk factor of vaccine preventable infectious diseases due to the altered immune system and the natural evolution of the disease. There are differences in the prescription of some vaccines for this population. The aim of this study is to elaborate a vaccination protocol for chronic kidney disease and haemodialysis patients for a better immunization coverage, care and prevention against preventable infectious diseases.

Methods The study was conducted by a multidisciplinary team composed by pharmacists, infectious disease paediatrician and nephrology paediatricians. After a literature research (in Medline with MeSH terms: 'Kidney Failure, Chronic', 'Renal Dialysis' and 'Vaccines') ${ }^{1}{ }^{2}$, we compared the French immunization schedule $^{3}$ for the general population with patient with chronic kidney disease or haemodialysis patients and confront it to the physician practice in our nephrology unit. For each vaccine, we collected the following data: indication, any difference concerning dose, schedule, re-administration, antibody titration and reason for these differences.

Results The literature analysis showed disparate practices among countries and even medical centres. The most concerned vaccines were: hepatitis $\mathrm{A}$ and $\mathrm{B}$ virus vaccine, pneumococcal vaccine, flu and measles vaccines. The difference between vaccine scheduled concerned the indication (meningococcus A, B, C, Y and W135, papillomavirus), dose (hepatitis $\mathrm{B}$ ), the schedule (hepatitis $\mathrm{B}$, hepatitis $\mathrm{A}$, pneumococcal, measles), re-administration (hepatitis $\mathrm{B}$, varicella), antibody titration (hepatitis B, varicella). Patients with chronic kidney disease are more susceptible to develop hepatitis B infection. As for adult population, the haemodialysis patients are vaccinated with double dose ${ }^{4}$ of hepatitis $B$ vaccine. The antibodies 
titration at our hospital is made twice a year and anti-HBs level needed are 30 to $50 \mathrm{UI} / \mathrm{mL}$. Hepatitis A is a recommended vaccine for risk population including haemodialysis patients and chronic kidney disease patients. The vaccination schedule is the same for haemodialysis patients with two doses but the second dose is administered earlier, i.e. six months after the first with an antibody screening. For the pneumococcal vaccine, an additional dose is administered at 3 month of age for premature and at risk children and the conjugated vaccine potentiates the polyosidic vaccine. For measles, the second dose may be omitted if the antibody titration confirms the protection to allow the patient to be registered earlier on the renal transplant list. Flu vaccination is recommended with the same dose and schedule that the other patients, but tetravalent vaccines should always be chosen.

Conclusions Children with chronic kidney disease or on haemodialysis are more at risk of vaccine preventable infectious diseases and should be vaccinated earlier before beginning dialysis. The specific immunization schedule will be presented and may be used by other hospital and countries for concerned patients.

\section{REFERENCES}

1. Bakkaloğlu SA, et al. Vaccination Practices in Pediatric Dialysis Patients Across Europe. A European Pediatric Dialysis Working Group and European Society for Pediatric Nephrology Dialysis Working Group Study. Nephron 2018;138:280-286.

2. Costa NCP, da Canhestro MR, Soares CMBM \& Rodrigues JS. Monitoring of postvaccination anti-HBs titles vaccine in children and adolescents in the pre-dialysis of chronic kidney disease. Braz. J. Nephrol. 2017;39:296-304.

3. DGS_Anne.M, DICOM_Jocelyne.M, DGS_Anne.M \& DICOM_Jocelyne.M. Le calendrier vaccinal. Ministère des Solidarités et de la Santé (2019). Available at: https://solidarites-sante.gouv.fr/prevention-en-sante/preserver-sa-sante/vaccination/ calendrier-vaccinal (Accessed: 28th June 2019)

4. Misurac JM, et al. Immunogenicity of augmented compared with standard dose hepatitis B vaccine in pediatric patients on dialysis: a midwest pediatric nephrology consortium study. Clin. J. Am. Soc. Nephrol 2017;12:772-778.

\section{P45 ENOXAPARIN AND TINZAPARIN IN PEDIATRICS: IMPACT OF PRESCRIPTION RECOMMENDATIONS ON PRESCRIPTION QUALITY AND ANTI-XA LEVELS}

\begin{abstract}
${ }^{1} J u l i e$ Noailly, 'Lailly Sadozaï, ${ }^{2}$ Marie-Françoise Hurtaud-Roux, ${ }^{3}$ Jérome Naudin, ${ }^{4}$ Ronan Bonnefoy, ${ }^{5}$ Caroline Farnoux, ${ }^{6}$ Thérésa Kwon, ${ }^{7}$ Olivier Bourdon, ${ }^{8}$ Sonia ProtLabarthe*. ${ }^{1}$ Service de Pharmacie, AP-HP, Hôpital Robert-Debré, Paris, France; ${ }^{2}$ Service d'Hématologie, AP-HP, Hôpital Robert-Debré, Paris, France; ${ }^{3}$ Senvice de Réanimation Pédiatrique, AP-HP, Hôpital Robert-Debré, Paris, France; ${ }^{4}$ Service de Cardiologie Pédiatrique, AP-HP, Hôpital Robert-Debré, Paris, France; ${ }^{5}$ Service de Néonatologie, AP-HP, Hôpital Robert-Debré, Paris, France; ${ }^{6}$ Senvice de Néphrologie Pédiatrique, AP-HP, Hôpital RobertDebré, Paris, France; ${ }^{7}$ Service de Pharmacie, AP-HP, Hôpital Robert-Debré, Département de pharmacie clinique, Université Paris Descartes, Paris, France; ${ }^{8}$ Service de Pharmacie, AP-HP, Hôpital Robert-Debré, Université de Paris, ECEVE, Inserm, Paris, France
\end{abstract}

\subsection{6/archdischild-2020-NPPG.54}

Aims Enoxaparin and tinzaparin, two low-molecular-weight heparins (LMWH), are used in paediatrics with multiples advantages such as facility of administration, reduced frequency of side effects, reduced drug interaction. However, their use is at higher risk of error in prescription, dosage, dilution or administration. ${ }^{1}$ The monitoring of efficacy is based on the dosage of anti-Xa level with a target between 0.5 and $1 \mathrm{IU} / \mathrm{mL}(0.4$ to $1.2 \mathrm{IU} / \mathrm{mL}$ tolerated in our hospital). ${ }^{2,3,4}$ This dosage is performed on a routine basis in patients with curative treatment. A protocol was written by a multidisciplinary team (nephrologist, neonatologist, haematologist, cardiologist, paediatrician and pharmacist) in order to standardize the prescriptions of LMWH within the hospital for patients aged between 0 and 18. The aim of this study consists in the analysis of prescriptions of enoxaparin and tinzaparin and the anti-Xa levels before/after the dissemination of the protocol during the summer of 2017.

Methods This is a retrospective observational study in our mother-child teaching hospital in France. Any patient hospitalized in 2016 and 2018 and who received a prescription for enoxaparin or tinzaparin was included in the study. Exclusion criteria were: patients hospitalized in obstetrics and gynaecology and patients over 18 years old. Prescribing throughout the hospital is computerized and involves PCS $^{\circledR}$ software (IBM, Armonk, NY, USA). Data collected concerned the patient (age, weight, first anti-Xa level, unit), the drug prescribed (dosage expressed in IU, first dosage expressed in IU/ $\mathrm{kg}$ depending on the patient's age and/or weight, the frequency of administration and the dilution when necessary and if it is conform to the protocol). This study has been approved by our ethics review board in March 2019.

Results In 2016 2,246 prescriptions for 630 patients were analyzed (601 patients had only enoxaparin, 7 only tinzaparin and 22 had a switch between the two heparins). In 2018 we studied 2,061 prescriptions for 629 patients (591 patients had only enoxaparin, 10 only tinzaparin and 28 had a switch). The conformity was improved concerning the first dose expressed in $\mathrm{IU} / \mathrm{kg}(34.8 \%$ then $52.1 \%$ for enoxaparin and $69.2 \%$ then $80.0 \%$ for tinzaparin), the dosage and frequency (28.7\% then $43.8 \%$ for enoxaparin and $69.2 \%$ then $80.0 \%$ for tinzaparin), the dilution specified $(66.7 \%$ then $73.1 \%)$ and the dilution conform to protocol $(29.4 \%$ then $66.4 \%)$. However, we observed a slight decrease in the conformity concerning the unit in IU/administration $(84.5 \%$ then $80.2 \%)$ with dose expressed in $\mathrm{mL}, \mathrm{mg}$ or 'referred to protocol'. The rate of conform first anti-Xa levels (between 0.4 and $1.2 \mathrm{IU} / \mathrm{mL}$ ) improved from $26.6 \%$ among 158 dosages in 2016 to $44.1 \%$ among 118 dosages in 2018.

Conclusions The overall results show an improvement in the prescription of enoxaparin and tinzaparin and in the anti-Xa levels since the dissemination of the protocol for prescribing physicians. This whole protocol will be presented in the poster and may be used by other hospitals.

\section{REFERENCES}

1. Fanikos J, Stapinski C, Koo S, et al. Medication errors associated with anticoagu lant therapy in the hospital. Am J Cardiol 2004;94:532-535.

2. Monagle P, Chan AKC, Goldenberg NA, et al. Antithrombotic therapy in neonates and children: Antithrombotic Therapy and Prevention of Thrombosis, 9th ed: American College of Chest Physicians Evidence-Based Clinical Practice Guidelines, Chest. 2012;141:e737S-e801S.

3. Andrade-Campos MM, Montes-Limón AE, Fernandez-Mosteirin N, et al. Dosing and monitoring of enoxaparin therapy in children: experience in a tertiary care hospital. Blood Coagul Fibrinolysis. Int J Haemost Thromb 2013:24:194-8.

4. Ahuja TM, Mousavi L, Klejmont, et al. Enoxaparin dosing and antiXa monitoring in specialty populations: a case series of renal-impaired, extremes of body weight, pregnant, and pediatric patients. J Formul Manag 2018;43:609-614.

\section{P46 DOSE-BANDING LIMITS FOR COMMONLY PRESCRIBED MEDICATIONS FOR CHILDREN IN THE UK}

${ }^{1}$ Asia N Rashed, ${ }^{2}$ Stephen Tomlin*. 'King's College London, UK; Evelina London Children's Hospital, Guy's and St Thomas' NHS Foundation Trust, UK; ' ${ }^{2}$ Great Ormond Street Hospital for Children NHS Foundation Trust, UK

10.1136/archdischild-2020-NPPG.55

Aim Currently, majority of prescribed medication doses are calculated according to a child's body weight without 